\title{
Comprehensive fire behaviour assessment of polymeric materials based on cone calorimeter investigations
}

\author{
Bernhard Schartel *, Ulrike Braun \\ Federal Institute for Materials Research and Testing, Unter den Eichen 87, \\ 12205 Berlin, Germany; Fax +49 (0) 308104 1037; bernhard.schartel@bam.de
}

(Received: November 19, 2002; published: April 1, 2003)

\begin{abstract}
Bench scale performance based cone calorimeter investigations were conducted on glass fibre reinforced polyamide 66 (PA-66) and high impact polystyrene (HIPS) materials. Red phosphorus and magnesium hydroxide were used as fire retardants. Dilution, heat sink, barrier and charring mechanisms are considered to be active in the condensed phase. Dilution, cooling and flame poisoning mechanisms are discussed for the gas phase. Cone calorimeter data are used to give a comprehensive fire behaviour assessment in terms of the propensity to cause a quick growing fire and of the propensity to cause a fire of long duration. The external heat flux is varied between 30 and $75 \mathrm{~kW} / \mathrm{m}^{2}$ so that the results for combustion behaviour and flame retardancy, respectively, are valid for different fire scenarios and fire tests. Results on the intrinsic contribution of the steady heat release rate per unit area reveal information about the flammability behaviour. UL 94 results are predicted in close correspondence to UL 94 experiments.
\end{abstract}

\section{Introduction}

Today the bench scale performance based cone calorimeter is widely used to compare and to rank materials in a quantitative way with respect to fire risks (heat release, time to ignition, etc.) and fire hazard (CO production, smoke production) [1]. It is an especially suitable tool in the field of developing fire retarded polymeric materials. Mostly it is used to screen different materials or demonstrate fire retardancy effects so that the number of cone calorimeter tests performed for each material is quite small and that they yield largely qualitative conclusions.

By contrast, the challenge presented by this paper is to offer a comprehensive fire behaviour assessment by means of cone calorimeter investigations. Therefore, one goal is to demonstrate that the variation of the external heat flux in cone calorimeter investigations makes such a comprehensive fire behaviour assessment possible. In comparison to studies, which are restricted to one external heat flux, the results of this study can be used to evaluate different fire scenarios and fire tests. Furthermore, the effect of fire retardancy mechanisms on fire response can be characterized as a function of various fire conditions. Hence, an expanded cone calorimeter study not only contributes information with respect to practical considerations, but also with respect to the scientific understanding of fire retardancy mechanisms. 
Two polymeric materials, glass fibre reinforced polyamide 66 (PA-66) and high impact polystyrene (HIPS), and the fire retardants red phosphorus and magnesium hydroxide $\left(\mathrm{Mg}(\mathrm{OH})_{2}\right)$ are chosen as model systems. These model systems represent a variety of different fire retardancy features while maintaining good comparability for interpretation. Red phosphorus can act both in the condensed phase and in the gas phase $[2,3]$. Indeed, it is reported to work in the condensed phase in the case of glass fibre reinforced PA-66 [4,5], but is known to be a gas phase flame poisoning agent for HIPS materials [6]. Barrier mechanisms as well as formation of thermal stable char were identified for glass fibre reinforced PA-66 / red phosphorus systems $[4,5]$. The use of red phosphorus in glass fibre reinforced PA-66 marks an area where it is particularly suited for applications [7]. $\mathrm{Mg}(\mathrm{OH})_{2}$ yields a thermally stable inorganic magnesia $(\mathrm{MgO})$ residue, which is characterized by a high heat capacity $[8,9]$ and is proposed to work as a protection layer $[9,10,11]$, whereas the hydrocarbonaceous char promoted by red phosphorus in PA-66 can be decomposed at higher temperatures. Three examples of typical tasks of fire performance assessment are discussed in detail:

- fire retardancy based on different fire retardants,

- effect of fire retardancy mechanisms for different external heat fluxes,

- prediction of the performance in fire tests like UL 94.

\section{Experimental part}

\section{Materials}

Several glass fibre reinforced polyamide 66 (PA-66) materials, Ultramid ${ }^{\circledR}$ (BASF AG, Germany), were investigated: A3EG5, A3EG7, A3X3G5, A3X3G7, A3X2G5, A3X2G7, A3XZG7. $X$ indicates that the material contains red phosphorus. G5 and G7 represent a glass fibre content of around 25 and $35 \mathrm{wt.} \%$, respectively. High impact polystyrene (HIPS), HIPS containing 10 wt.-\% red phosphorus, HIPS containing 15 wt.- $\%$ magnesium hydroxide $\left(\mathrm{Mg}(\mathrm{OH})_{2}\right)$, and HIPS containing 10 wt.- $\%$ red phosphorus and $15 \mathrm{wt} .-\% \mathrm{Mg}(\mathrm{OH})_{2}$ were investigated. All of the HIPS systems were provided by BASF AG (Germany). Compounding was done via extrusion to homogenous materials in granulate form. Plates $(10 \mathrm{~cm} \times 10 \mathrm{~cm}, 2.8 \mathrm{~mm}$ thick) were prepared via injection moulding and used in the cone calorimeter investigations for all of the systems. Compounding and injection moulding were done in the technical scale laboratory in BASF AG to reach an industrial preparation standard.

\section{Cone calorimeter}

A cone calorimeter (Fire Testing Technology, UK) in accordance with ASTM E 1354 / ISO 5660 was used to study combustion behaviour. External heat flux was varied between 30 and $75 \mathrm{~kW} / \mathrm{m}^{2}$. The thickness of the samples was thin as compared to the recommendation of the ASTM E 1354 / ISO 5660 standard, but corresponds to a realistic thickness with respect to applications. All samples were measured in a horizontal position using a retainer frame to reduce unrepresentative edge burning; the corresponding decreased surface area of the sample $\left(88.36 \mathrm{~cm}^{2}\right)$ was used for data evaluation. 


\section{Results and discussion}

\section{Database for comprehensive fire assessment}

In the cone colorimeter, materials respond to a forced flaming combustion. The fire risks are characterized by measures like time to ignition, peak of the heat release rate, total heat evolved and averaged heat release rate. The expected steady heat release rate per unit area $\left(\dot{q}_{c}^{\text {avg }}\right)$ for the cone calorimeter set-up can be written as $[12,13,14,15]$ :

$\dot{q}_{c}^{\text {avg }}=\chi h_{c}^{0} \dot{m}_{g}^{\text {avg }}=\chi h_{c}^{0} \frac{\dot{q}_{\text {net }}}{L_{g}}=\chi(1-\mu) \frac{h_{c}^{0}}{h_{g}}\left(a \dot{q}_{\text {ext }}+a \dot{q}_{\text {flame }}-\dot{q}_{\text {rerad }}\right)$

with $\chi=$ combustion efficiency in the flame, $h_{c}^{0}=$ heat of complete combustion of the fuel gases, $\quad \dot{m}_{g}^{\text {avg }}=$ mass flux of fuel gases, $\quad \dot{q}_{\text {net }}=$ net heat flux, $L_{g}=$ heat of gasification per unit mass of volatiles, $\mu=$ char yield, $h_{g}=$ heat of gasification, $a=$ absorptivity, $\quad \dot{q}_{\text {ext }}=$ external heat flux, $\dot{q}_{\text {flame }}=$ heat flux from the surface flame, $\dot{q}_{\text {rerad }}=\varepsilon \sigma T_{s}^{4}=$ heat flux reradiated to the environment, $\varepsilon=$ emissivity, $\sigma=$ Boltzmann constant, $T_{s}=$ burning surface temperature.

Separating intrinsic and extrinsic parts, using the heat release parameter $(H R P)$ and the intrinsic heat release rate $\left(H R R_{0}\right)$ results in $[12,13,14]$ :

$\dot{q}_{c}^{\text {avg }}=H R R_{0}+H R P \dot{q}_{\text {ext }}$

with $H R R_{0}=\chi(1-\mu) \frac{h_{c}^{0}}{h_{g}}\left(a \dot{q}_{\text {flame }}-\dot{q}_{\text {rerad }}\right)$

and $H R P=\chi(1-\mu) \frac{h_{c}^{0}}{h_{g}} a$

It should be noted that this model description does not properly take into account heat transfer aspects, which may become predominant for charring materials. However, such contributions can be considered, e.g., using an additional contribution to the heat flux reradiated to the environment. The value corresponding to the steady heat release rate was determined from cone calorimeter data as proposed by Lyon [12] for thick charring, intermediate thick and thin samples, respectively. The complexity of the systems due to such factors as the influence of filler, fire retardants or even the combination of different agents and effects yields heat release rate curves, some of which cannot be classified unequivocally. Added to statistical deviations, this systematic uncertainty results in a level of high vagueness in the intrinsic heat release rate values. Fig. 1 shows the steady heat release rates and the total heat evolved for a glass fibre reinforced PA-66 system, without and with red phosphorus, versus the external heat flux. The intrinsic heat release rate is indicated as an intercept, whereas the heat release parameter corresponds to the slope of the steady heat release rate curve.

Tab. 1 and Tab. 2 summarize the measures for fire risks as well as the calculated heat release parameter and intrinsic heat release rate. To characterize the heat release, which is the main fire risk, the total heat release and the peak of the heat release rate are summarized, which are also considered explicitly in the following 
discussions. The errors given in Tab. 1 and Tab. 2 represent a conservative error approximation. They are dominated by determination uncertainties being independent of the measured values. Statistical deviations are of minor importance, which is due to the high reproducibility of sample preparation. It should be noted that other characteristics of the heat release rate besides its peak play a role, such as the different heat release rates averaged for certain time points or the steady heat release rate. In accordance with their different definitions, these characteristic measures differ from each other, especially quantitatively. As a result, the relative reduction in terms of the peak of the heat release rate comparing A3EG5 and A3X2G5 for an external heat flux of $70 \mathrm{kw} / \mathrm{m}^{2}$, e.g., is $54 \%$ (Tab. 2) and translates to an only $34 \%$ reduction in the steady heat release rate (Fig 1 ). However, since the qualitative interpretation does not differ, we will focus on just one characteristic measure for the figures and tables, the peak of the heat release rate. In the discussion, the term 'heat release rate(s)' is used to deal with the heat release in general without focusing on such a special heat release characteristic like peak of the heat release or a heat release rate average for a certain time point.

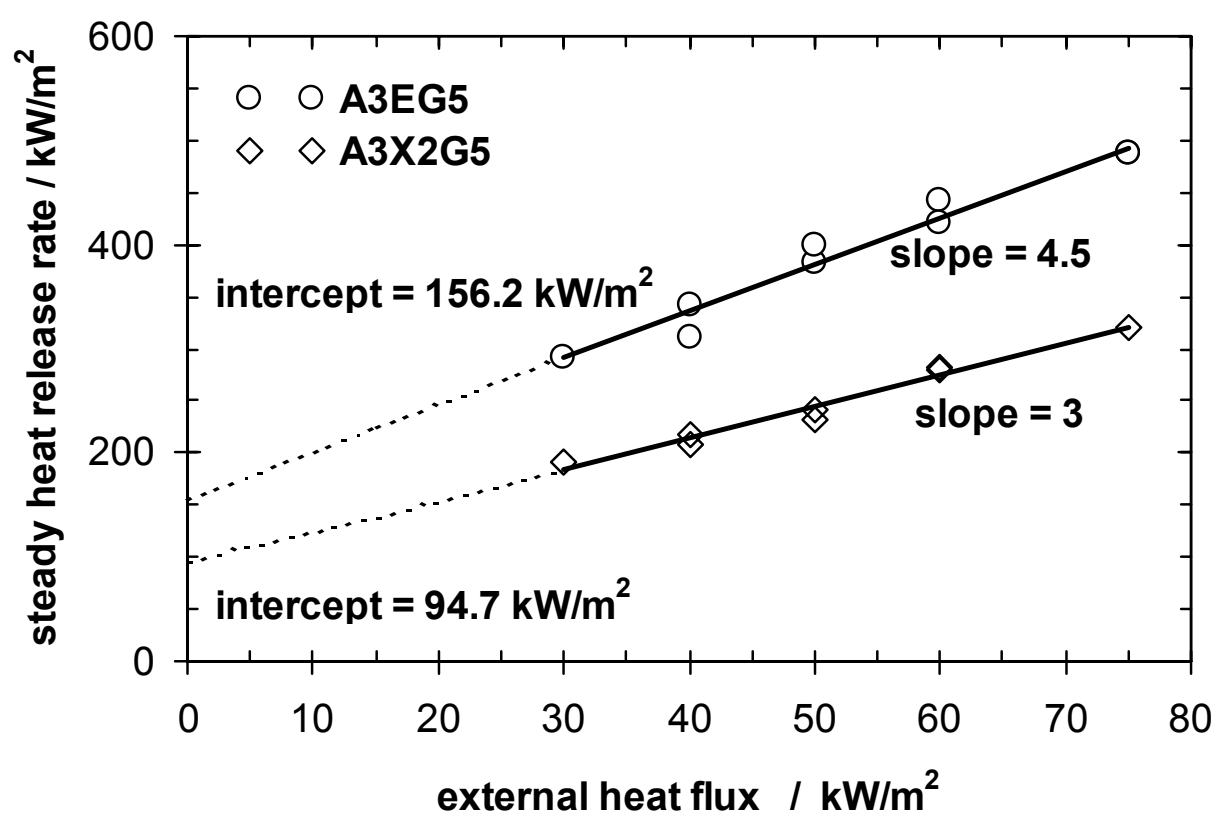

Fig. 1. Steady heat release rates versus external heat flux for A3EG5 and A3X2G5 illustrating the heat release parameter and the intrinsic heat release rate as slope and intercept, respectively

Since the values are monitored for various external heat fluxes, the data in Tab. 1 and Tab. 2 represent also a valuable characterization of the fire behaviour and fire retardancy effect in terms of fire risks with respect to different fire scenarios and fire tests. In general, the time to ignition determines the ease of ignition. The peak of the heat release rate and time to peak of the heat release rate govern the flame spread. The total heat evolved corresponds to the fire load. However, it should be noted that in real fire scenarios of components or structures these properties are not independent of each other. How to use the data in detail is demonstrated by three examples in the following discussion. 
Tab. 1. Fire risks versus external heat flux for samples containing HIPS; values are averaged based on cone calorimeter measurements in duplicate

\begin{tabular}{|c|c|c|c|c|c|c|c|}
\hline \multirow[t]{3}{*}{ Sample } & \multirow{2}{*}{$\begin{array}{l}\text { Heat } \\
\text { flux in } \\
\mathrm{kW} / \mathrm{m}^{2}\end{array}$} & \multirow{2}{*}{$\begin{array}{c}\text { Time } \\
\text { to } \\
\text { ignition } \\
\text { in } \mathrm{s}\end{array}$} & \multirow{2}{*}{$\begin{array}{c}\text { Total } \\
\text { heat } \\
\text { evolved } \\
\text { in } \mathrm{MJ} / \mathrm{m}^{2}\end{array}$} & \multicolumn{2}{|c|}{$\begin{array}{l}\text { Peak of the heat } \\
\text { release rate in }\end{array}$} & \multirow{2}{*}{$\begin{array}{c}\text { Heat } \\
\text { release } \\
\text { parameter }\end{array}$} & \multirow{2}{*}{$\begin{array}{l}\text { Intrinsic heat } \\
\text { release rate } \\
\text { in } \mathrm{kW} / \mathrm{m}^{2}\end{array}$} \\
\hline & & & & $\mathrm{kW} / \mathrm{m}^{2}$ & $\mathrm{~s}$ & & \\
\hline & $\begin{array}{c} \pm 1 \\
\mathrm{~kW} / \mathrm{m}^{2}\end{array}$ & $\pm 2 \mathrm{~s}$ & $\begin{array}{c} \pm 5 \\
\mathrm{MJ} / \mathrm{m}^{2}\end{array}$ & $\begin{array}{c} \pm 10 \\
\mathrm{~kW} / \mathrm{m}^{2}\end{array}$ & $\pm 5 \mathrm{~s}$ & \pm 1 & $\pm 25 \mathrm{~kW} / \mathrm{m}^{2}$ \\
\hline \multirow[t]{3}{*}{ HIPS } & 30 & 97 & 78 & 742 & 303 & 2.9 & 333.7 \\
\hline & 50 & 40 & 90 & 1124 & 218 & & \\
\hline & 70 & 22 & 91 & 1478 & 168 & & \\
\hline \multirow{3}{*}{$\begin{array}{c}\text { HIPS/red } \\
\text { phosphorus }\end{array}$} & 30 & 83 & 60 & 341 & 265 & 3.2 & 172 \\
\hline & 50 & 27 & 53 & 457 & 170 & & \\
\hline & 70 & 16 & 55 & 570 & 133 & & \\
\hline HIPS/ & 30 & 111 & 91 & 466 & 143 & 3.5 & 346.5 \\
\hline \multirow[t]{2}{*}{$\mathrm{Mg}(\mathrm{OH})_{2}$} & 50 & 41 & 85 & 489 & 73 & & \\
\hline & 70 & 25 & 83 & 605 & 50 & & \\
\hline HIPS/red & 30 & 101 & 54 & 203 & 130 & 2 & 97.1 \\
\hline phosphorus/ & 50 & 38 & 53 & 256 & 65 & & \\
\hline $\mathrm{Mg}(\mathrm{OH})_{2}$ & 70 & 21 & 55 & 303 & 48 & & \\
\hline
\end{tabular}

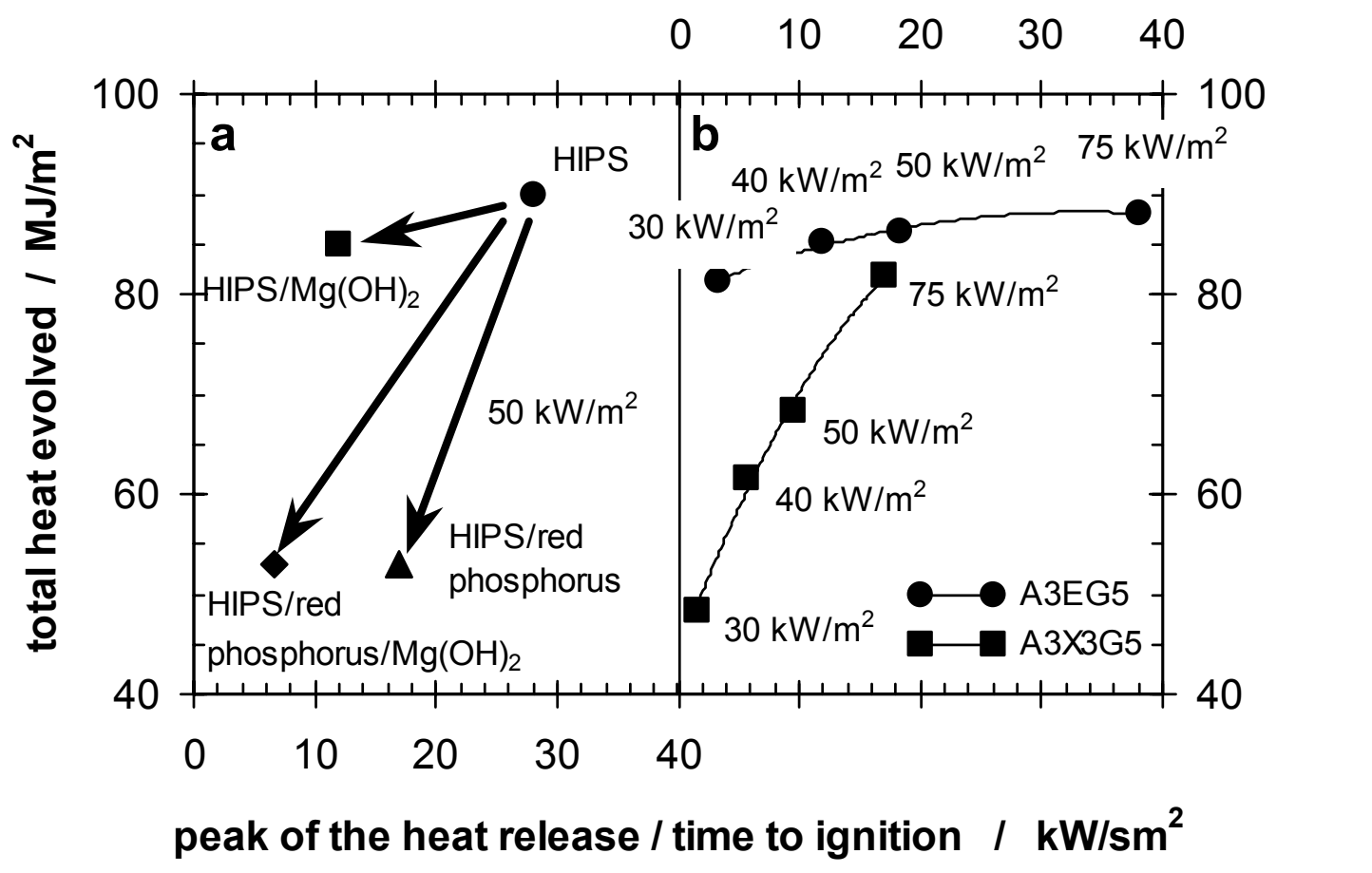

Fig. 2. Total heat evolved versus the quotient of the peak of the heat release rate and the time to ignition for (a) HIPS, HIPS/red phosphorus, HIPS/Mg $(\mathrm{OH})_{2}, \mathrm{HIPS} / \mathrm{red}$ phosphorus $/ \mathrm{Mg}(\mathrm{OH})_{2}$, with an external heat flux of $50 \mathrm{~kW} / \mathrm{m}^{2}$ applied, (b) A3EG5 and A3X3G5, varying the external heat fluxes between 30 and $75 \mathrm{~kW} / \mathrm{m}^{2}$ 
Tab. 2. Fire risks vs. external heat flux for samples based on glass fibre reinforced PA-66; values are averaged based on cone calorimeter measurements in duplicate

\begin{tabular}{|c|c|c|c|c|c|c|c|}
\hline \multirow[t]{2}{*}{ Sample } & \multirow{2}{*}{$\begin{array}{l}\text { Heat } \\
\text { flux in } \\
\mathrm{kW} / \mathrm{m}^{2}\end{array}$} & \multirow{2}{*}{$\begin{array}{l}\text { Time to } \\
\text { ignition } \\
\text { in } s\end{array}$} & \multirow{2}{*}{$\begin{array}{c}\text { Total } \\
\text { heat } \\
\text { evolved } \\
\text { in } \mathrm{MJ} / \mathrm{m}^{2}\end{array}$} & \multicolumn{2}{|c|}{$\begin{array}{l}\text { Peak of the heat } \\
\text { release rate in }\end{array}$} & \multirow{2}{*}{$\begin{array}{c}\text { Heat } \\
\text { release } \\
\text { parameter }\end{array}$} & \multirow{2}{*}{$\begin{array}{l}\text { Intrinsic heat } \\
\text { release rate } \\
\text { in } \mathrm{kW} / \mathrm{m}^{2}\end{array}$} \\
\hline & & & & $\mathrm{kW} / \mathrm{m}^{2}$ & $\mathrm{~s}$ & & \\
\hline & $\begin{array}{c} \pm 1 \\
\mathrm{~kW} / \mathrm{m}^{2}\end{array}$ & $\pm 2 \mathrm{~s}$ & $\begin{array}{c} \pm 5 \\
\mathrm{MJ} / \mathrm{m}^{2}\end{array}$ & $\begin{array}{c} \pm 10 \\
\mathrm{~kW} / \mathrm{m}^{2}\end{array}$ & $\pm 5 \mathrm{~s}$ & \pm 1 & $\pm 25 \mathrm{~kW} / \mathrm{m}^{2}$ \\
\hline \multirow[t]{5}{*}{ A3EG5 } & 30 & 110 & 81.3 & 354 & 300 & 4.5 & 156.2 \\
\hline & 40 & 74 & 84.7 & 383 & 134 & & \\
\hline & 50 & 42 & 83.6 & 520 & 122 & & \\
\hline & 60 & 30 & 89.6 & 619 & 98 & & \\
\hline & 75 & 19 & 88.8 & 721 & 86 & & \\
\hline \multirow[t]{4}{*}{ A3X3G5 } & 40 & 65 & 54.3 & 133 & 117 & 2.9 & 86.5 \\
\hline & 50 & 39 & 62.8 & 222 & 63 & & \\
\hline & 60 & 27 & 74 & 269 & 53 & & \\
\hline & 75 & 18 & 75.3 & 303 & 45 & & \\
\hline \multirow[t]{5}{*}{ A3X2G5 } & 30 & 89 & 52.2 & 192 & 120 & 3 & 94.7 \\
\hline & 40 & 62 & 66.6 & 213 & 83 & & \\
\hline & 50 & 37 & 64.0 & 237 & 63 & & \\
\hline & 60 & 28 & 77.4 & 280 & 57 & & \\
\hline & 75 & 18 & 80.7 & 320 & 42 & & \\
\hline \multirow[t]{5}{*}{ A3XZG5 } & 30 & 101 & 48.4 & 158 & 138 & 2.9 & 90.0 \\
\hline & 40 & 70 & 59.1 & 209 & 92 & & \\
\hline & 50 & 41 & 64.2 & 237 & 77 & & \\
\hline & 60 & 31 & 70.5 & 267 & 54 & & \\
\hline & 75 & 19 & 80.3 & 310 & 54 & & \\
\hline \multirow[t]{5}{*}{ A3EG7 } & 30 & 113 & 79 & 372 & 276 & 3 & 159.4 \\
\hline & 40 & 71 & 77.1 & 364 & 186 & & \\
\hline & 50 & 43 & 73.7 & 472 & 128 & & \\
\hline & 60 & 31 & 83.2 & 552 & 92 & & \\
\hline & 75 & 21 & 80.3 & 647 & 77 & & \\
\hline \multirow[t]{5}{*}{ A3X3G7 } & 30 & 117 & 25.2 & 101 & 144 & 2.0 & 97.9 \\
\hline & 40 & 68 & 51 & 167 & 84 & & \\
\hline & 50 & 43 & 56.2 & 194 & 66 & & \\
\hline & 60 & 31 & 63.3 & 221 & 53 & & \\
\hline & 75 & 20 & 57.4 & 249 & 39 & & \\
\hline \multirow[t]{5}{*}{ A3X2G7 } & 30 & 98 & 29.2 & 127 & 123 & 1.9 & 101.9 \\
\hline & 40 & 66 & 42.7 & 176 & 84 & & \\
\hline & 50 & 41 & 56.8 & 187 & 62 & & \\
\hline & 60 & 30 & 61.2 & 225 & 48 & & \\
\hline & 75 & 20 & 62 & 236 & 44 & & \\
\hline
\end{tabular}




\section{Fire retardancy based on different fire retardants (example 1)}

Fig. 2a illustrates the fire retardancy effect of red phosphorus and $\mathrm{Mg}(\mathrm{OH})_{2}$ in HIPS for an external heat flux of $50 \mathrm{~kW} / \mathrm{m}^{2}$. The total heat evolved is plotted against the peak of the heat release rate / time to ignition according to Petrella [16]. Therefore, the ordinate can be interpreted as the propensity to cause a fire of long duration, whereas the abscissa is a measure of the propensity to cause a quickly growing fire. Obviously, sufficient fire retardancy reduces both of these significantly. It should be noted that most sources use the gradient of the growth of heat release (peak of the heat release rate / time to peak of the heat release rate) to describe a fire growth rate (FIGRA). However, both the quotient used in Fig. 2 for the abscissa and FIGRA monitor very similar features and illustrate the same information.

Adding $\mathrm{Mg}(\mathrm{OH})_{2}$ leads to several factors that influence the fire response of polymeric materials [9]. Obviously, adding 15 wt.-\% inorganic material significantly dilutes the combustible organic material, resulting in a decrease in the total heat evolved. The endothermic reaction to $\mathrm{MgO}$ associated with formation and release of $\mathrm{H}_{2} \mathrm{O}$ not only works as a heat sink mechanism in the condensed phase, but the volatile $\mathrm{H}_{2} \mathrm{O}$ also acts as a dilution agent and as a very effective cooling agent in the gas phase. Additionally, the inorganic $\mathrm{MgO}$ residue works as a barrier at the surface of the condensed phase, thus suppressing the fuel support rate. This effect is not only due to its high heat capacity but also to the ceramic-like layer behaviour [8-11]. A decreased rate of mass loss results in a decreased heat release rate, as evident in the peak of the heat release rate (Tab. 1). The decreased thermal feedback from the flame zone enhances the fire-retardant effect such that the mechanism is selfenhancing. Beyond the peak of the heat release rate, the time to ignition is increased (Tab. 1) due to the cooling mechanisms and heat capacity of the filler, respectively. Both effects, increasing the time to ignition and decreasing the peak of the heat release rate, improve the flame spread properties (Fig. 2a). Since the entire polymer is still combusted, the burning time is increased in accordance with the decreased heat release rate. The total heat evolved / total mass loss - averaged, taking into account all measurements for each material - seems to increases from $2.89 \pm 0.09$ $\mathrm{MJ} \cdot \mathrm{g}^{-1} \cdot \mathrm{m}^{-2}$ for HIPS up to $2.98 \pm 0.11 \mathrm{MJ} \cdot \mathrm{g}^{-1} \cdot \mathrm{m}^{-2}$ for HIPS/Mg(OH) $)_{2}$. It is proposed that the reduced fuel support entails better-ventilated combustion such that, consequently, a slight increase in the heat release per polymer mass loss is observed in comparison with the pure polymer material. With regard to the total heat evolved, the two effects, decrease of the amount of polymeric fuel and increase of heat evolved per mass of polymeric fuel, are of the same order of magnitude. The influence on the total heat evolved is in the range of $0-10 \%$ (Tab. 1) and is not significant with respect to fire retardancy.

Adding red phosphorus to HIPS results in heat release being significantly decreased (Tab. 1). Since no char or residue formation is observed, evaporated phosphorus species can be proposed, which cause a radical trapping mechanism in the gas phase. Probable reactions leading to flame inhibition have been proposed before [17]. Indeed, the total heat evolved / total mass loss - averaged, taking into account all measurements for each material - is reduced from $2.89 \pm 0.09 \mathrm{MJ} \cdot \mathrm{g}^{-1} \cdot \mathrm{m}^{-2}$ for HIPS to $1.81 \pm 0.09 \mathrm{MJ} \cdot \mathrm{g}^{-1} \cdot \mathrm{m}^{-2}$ for HIPS/red phosphorus. Therefore, besides the dilution effect caused by replacing 10 wt.-\% organic material with inorganic red phosphorus, red phosphorus works mainly as a flame poisoning agent in HIPS. Unfortunately, the time to ignition is reduced (Tab. 1), which can be due to a decreased specific heat capacity, decreased ignition temperature or changed decomposition products of the blend as compared to HIPS. However, the total heat evolved and the heat release 
rates are decreased in comparison to HIPS (Tab. 1). The effect on the heat release rates is even self-reinforcing, since the decreased thermal feedback from the flame zone leads to smaller fuel production in the pyrolysis zone. In terms of Eq. (1), the factors heat of complete combustion of the fuel gases and heat flux from the surface flame are reduced. An analogous influence on the heat release rate and total heat evolved can be expected for stable char-forming materials if the barrier effect of the char layer is not the dominant property. Such charring implies flame retardancy due to the reduction of factor 1 minus char yield and of the heat flux from the surface flame. This behaviour is illustrated by the PA-66 / red phosphorus system for smaller heat fluxes (data for $30 \mathrm{~kW} / \mathrm{m}^{2}$ in Fig. 2b), for which the red phosphorus is active mainly in the condensed phase promoting char formation.

Using $\mathrm{Mg}(\mathrm{OH})_{2}$ and red phosphorus as fire retardants in HIPS presents the possibility of combining the described mechanisms in the condensed phase and gas phase. In fact, this combination shows the best fire retardancy of the investigated HIPS materials (Fig. 2a). The characteristics are described as a first approximation qualitatively through superposition. However, the processes do not occur totally independently of each other. The total heat evolved / total mass loss - averaged, taking into account all measurements for each material - was found, e.g., to be $1.93 \pm 0.09$ $\mathrm{MJ} \cdot \mathrm{g}^{-1} \cdot \mathrm{m}^{-2}$ as compared to $1.81 \pm 0.09 \mathrm{MJ} \cdot \mathrm{g}^{-1} \cdot \mathrm{m}^{-2}$ for HIPS/red phosphorus, $2.89 \pm$ $0.09 \mathrm{MJ} \cdot \mathrm{g}^{-1} \cdot \mathrm{m}^{-2}$ for HIPS and $2.98 \pm 0.11 \mathrm{MJ} \cdot \mathrm{g}^{-1} \cdot \mathrm{m}^{-2}$ for HIPS $/ \mathrm{Mg}(\mathrm{OH})_{2}$. This slight antisynergism may be caused by a change in fire conditions generating not only longer burning times but also an increase of heat release per mass loss due to the improved ventilation. Thus, the further decrease of the heat release rates (Tab. 1$)$ is associated with a change in the concentrations of decomposition products in the gas phase. Furthermore, the phosphorus is partly fixed in the condensed phase as a stable Mg-phosphate residue, which is proved by both an increasing residue [18] and the chemical analysis using X-ray photoelectron spectroscopy (XPS) [18]. It is not surprising then that the combined material shows a slight anti-synergism in terms of the peak of the heat release rate and total heat evolved (Tab. 1, Fig. 2a). In contrast to this, the times to ignition are similar to the HIPS material (Tab. 1); this can be regarded as a synergism, since the increase found for $\mathrm{HIPS} / \mathrm{Mg}(\mathrm{OH})_{2}$ is not as high as the decrease in HIPS/red phosphorus systems.

\section{Effect of fire retardancy mechanisms for different external heat fluxes (example 2)}

Fig. 2b, Fig. 3 and Fig. 4 illustrate the fire retardancy effect of red phosphorus in glass fibre reinforced PA-66 and of red phosphorus and $\mathrm{Mg}(\mathrm{OH})_{2}$ in HIPS for various external heat fluxes. In Fig. $2 b$ the total heat evolved is plotted against the peak of the heat release rate, divided by time to ignition for PA-66 with and without red phosphorus. Fig. 3 and Fig. 4 illustrate the total heat evolved after the flame out and the peak of heat release rate, respectively, versus the external heat flux.

The heat release per mass loss is not changed significantly by adding red phosphorus in glass fibre reinforced PA-66 [4,5]. The material is transformed to a char-forming material. Therefore, the effective fire retardancy mechanism of red phosphorus is located in the condensed phase. The formed char works as a barrier and influences the pyrolysis temperature through its changed thermal feedback. The barrier property reduces the mass loss rate $[4,5]$ and tends to be largely independent of the external heat flux (Fig. 3, Tab. 2). Consequently, the fire retardancy increases for increasing external heat flux in terms of the heat release rate, as illustrated for the peak of the heat release rate in Fig. 4 and Tab. 2. The total heat evolved for the glass 
fibre reinforced PA-66 material without red phosphorus is largely independent of the external heat flux (Fig. 3, Tab 2). Since in first approximation the residue is given by the glass fibre content for all external heat fluxes [4,5], all the organic material becomes volatile and is combusted when burning ceases. Furthermore, no indication of a significant change of heat of combustion can be found. For systems with red phosphorus the total heat evolved is strongly dependent on the external heat flux (Fig. 3), since the fire-retarded system shows an increasing amount of stable char with decreasing external heat flux $[4,5]$.

All the experiments are characterized by a sustained flame zone, which results in an anaerobe decomposition zone, and the high temperature residue for thermogravimetry in air is clearly below the residue reached for small external heat fluxes [5]. Therefore, an increasing thermo-oxidative charring is ruled out as a possible mechanism resulting in an increasing amount of char for small external heat fluxes. Furthermore, thermogravimetry with different heating rates does not result in different amounts of residue [4,5], whereas the residue in the cone calorimeter experiments is increasing from 40 to nearly $65 \mathrm{wt} . \%$. Even though the thermogravimetry results cannot directly be compared to the cone calorimeter data, from this drastic difference also a changed weighting of different decomposition processes is ruled out as a possible mechanism. The effect is due to a decreasing effective pyrolysis temperature for decreasing external heat flux, resulting in an increasingly incomplete decomposition of the polymer [4,5]. This fire retardancy in terms of propensity for a fire of long duration vanishes for higher external heat fluxes (Fig. 2b). The influence exerted by diluting the organic material by adding red phosphorus is of minor importance in these systems in terms of the heat release rate and total heat evolved. The fire risk time to ignition cannot profit from the char layer that is built up during combustion. In fact it is even reduced (Tab. 2), which may be due to a decreased specific heat capacity, decreased ignition temperature, changed decomposition products or decreased decomposition temperature of the blend as compared to PA-66.

The total heat evolved for the HIPS material without and with red phosphorus is largely independent of the external heat flux, since as a first approximation all of the material is decomposed when burning ceases (Fig. 3). As discussed before, red phosphorus in HIPS acts mainly in the gas phase, reducing the heat release per mass loss due to incomplete combustion, which is hardly influenced by the external heat flux. In terms of the heat release rate the fire retardancy effect is reinforced due to the decreased thermal feedback from the flame zone for increasing external heat flux. Therefore the absolute difference of the heat release rates increases with increasing external heat flux, as illustrated for the peak of the heat release rate in Fig. 4.

The inorganic residue for HIPS systems containing $\mathrm{Mg}(\mathrm{OH})_{2}$ does not show any significant change against the external heat flux [18]. Therefore, the total heat evolved is nearly constant against external heat flux (Fig. 3). The origin of the peak of the heat release rate is changed in comparison to a non-charring system and corresponds to the formation of a sufficient protection layer. Since the MgO residue is stable against heat treatment, the heat release rate becomes nearly independent of the external heat flux (Fig. 4). Therefore, the fire retardancy effect in terms of the heat release rate increases with increasing external heat flux in comparison to HIPS. The peak of the heat release rate reduction for HIPS containing $15 \mathrm{wt} .-\% \mathrm{Mg}(\mathrm{OH})_{2}$ is of the same order as the reduction found for HIPS containing $10 \mathrm{wt} .-\%$ red phosphorus. However, the different mechanisms result in a different dependency from the external heat flux. The barrier effect becomes more effective for increasing external heat flux, 
but less effective for smaller external heat fluxes in comparison to the gas phase mechanism.

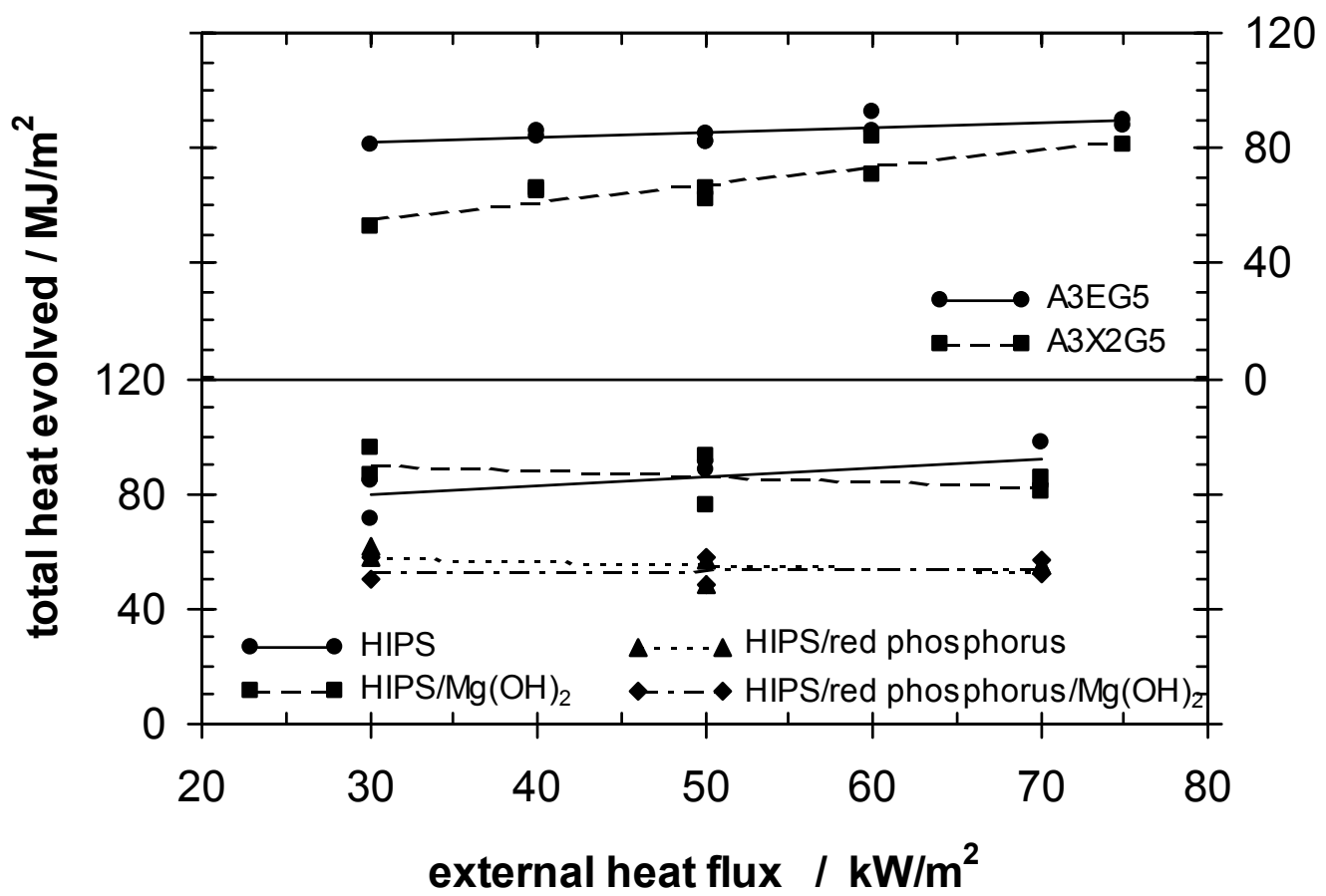

Fig. 3. Total heat evolved versus the external heat flux for A3EG5, A3X2G5, HIPS, HIPS/red phosphorus, HIPS/Mg $(\mathrm{OH})_{2}$, and HIPS/red phosphorus/Mg $(\mathrm{OH})_{2}$

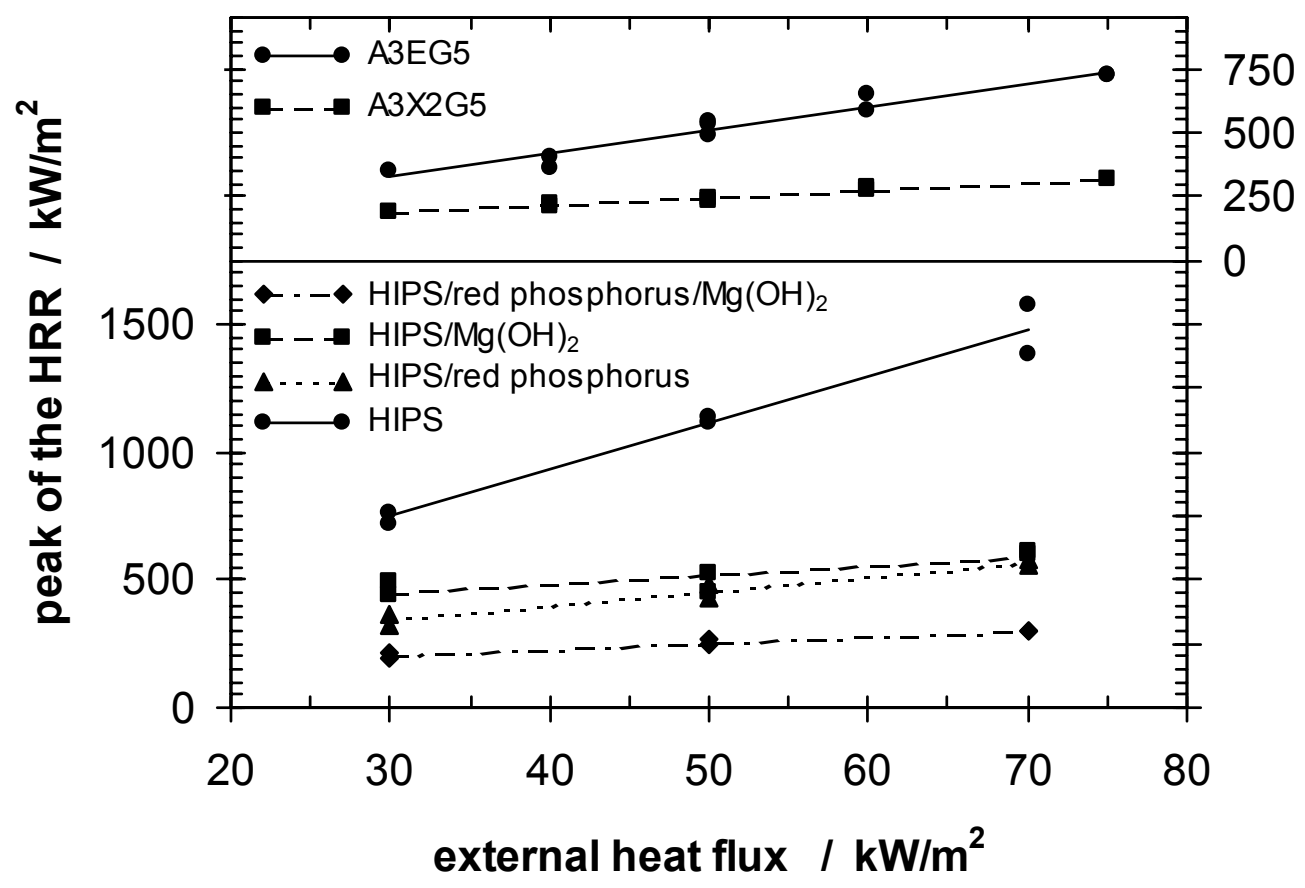

Fig. 4. Peak of the heat release rate (peak of the HRR) versus the external heat flux for A3EG5, A3X2G5, HIPS, HIPS/red phosphorus, HIPS/Mg(OH $)_{2}$, and HIPS/red phosphorus/Mg(OH $)_{2}$ 
Even though the data for the HIPS system containing $\mathrm{Mg}(\mathrm{OH})_{2}$ and red phosphorus are not, strictly speaking, given by superposition, but show a slight anti-synergism, their qualitative behaviour for different external heat flux (Tab. 1) can be explained as analogous to the systems HIPS/Mg(OH) $)_{2}$ and HIPS with red phosphorus (Fig. 2a, Fig. 3, Fig. 4). For all external heat fluxes applied, the polymeric material was found to decompose almost completely so that there is no significant dependence of the total heat evolved on the external heat flux. The enhancement of the decrease in terms of the heat release rate is due to the activity of two mechanisms: the barrier effect and the change of the heat release per mass of polymeric fuel.

Comparing the data of glass fibre reinforced PA-66 without and with red phosphorus, HIPS and HIPS fire retarded with red phosphorus and $\mathrm{Mg}(\mathrm{OH})_{2}$ clearly show the effects of external heat flux and different fire retardancy mechanisms on the fire response of materials. The characteristics are summarized in the following for two fire risks, total heat evolved and heat release rate.

The total heat evolved remains nearly unchanged for increasing external heat flux (Fig. 3), if the corresponding pyrolysis during a fire test of the system results in the same total amount of volatile products, and if the heat release per mass loss remains unchanged. The same total amount of volatile products is obviously expected in the case when the effective pyrolysis temperature is higher than the temperature range for complete decomposition. Then, in practice, only minor effects on the amount of residue or on the effective heat of combustion occur. Such minor effects can include a variation of the ventilation or temperature, for instance, and are of the same order of magnitude as the error range of the measurements. Systems for which an increasing pyrolysis temperature leads to a significant increasing conversion can show an increase in terms of total heat evolved for increasing external heat flux (Fig. 3 ). Beyond the formation of a thermally stable char, the total heat evolved can be reduced by reducing the loss of heat release per mass. This is the case for fire retardancy mechanisms like dilution and flame poisoning. The reduction is a good approximation, independent of the external heat flux, unless increasing heating rates or maximum surface temperatures significantly influence the processes. Barrier mechanisms do not significantly influence the total heat evolved, apart from minor effects.

The heat release rates and the time to ignition strongly depend on the external heat flux (Fig. 4). Dilution, flame poisoning and barrier effects decrease heat release rates with an increasing relative effectiveness for increasing external heat flux. The increasing relative effectiveness is caused by the fact that the fire retardancy is selfreinforced due to decreasing thermal feedback from the flame zone and/or the quotient of heat of complete combustion of the fuel gases and the heat of gasification per unit mass of volatiles. The formation of a thermally stable char works similar to a dilution in the gas phase. Instead of decreasing the heat of complete combustion of the fuel gases, the heat of gasification per unit mass of volatiles is increased in accordance with the increase of char yield. Both the dilution of combustible volatiles and char formation result in a decrease of thermal feedback from the flame zone so that the heat release parameter is decreased. Additionally, for charring systems the origin of the peak of the heat release rate is changed to the formation of a char layer and therefore its correlation is changed with respect to external heat treatment. The more decisive the barrier properties that are nearly independent of the external heat flux, the less dependent the heat release rate on the external heat flux. 
To correlate the results of different fire tests has proven to be problematic, even in cases for which different tests were invented for the same application. This is due to the fact that different fire tests try to simulate special fire scenarios. Hence, a whole zoo of parameters like dimension, source of ignition, ventilation, heat flux, geometry, etc. prevent easy and straightforward correlations, especially if different materials and fire retardancy mechanisms are considered. Even though the cone calorimeter is an optimised method with respect to obtaining performance based results, it is nevertheless still a special fire scenario. For instance, the samples are tested in a horizontal geometry under forced flaming conditions. Consequently, the cone calorimeter has a lack, for instance, in characterizing the fire behaviour of dripping materials. Insensitively dripping materials show artefacts for the mass loss rather than a flame out or a secondary ignition reported for other fire tests.

However, to overcome the difficulties of correlating the results of different fire tests, a comprehensive characterization of the fire response seems to be a promising approach. The variation of the external heat flux in the cone calorimeter delivers such a comprehensive characterization of the fire response for forced flaming combustion, if dripping effects can be neglected. Furthermore, the extrapolation to an external heat flux equal to zero was recently postulated to represent the fire response governing performance in flammability tests like UL 94 and the limiting oxygen index (LOI) [12]. It is obvious that the correlation between flammability tests and data obtained from forced flaming cone calorimeter investigations represents a sophisticated challenge. It is worth noting that UL 94 and LOI are widely accepted as the most important flammability tests for plastics so that, for instance, the prediction of UL 94 classification is also impressive and convincing. Tewarson [13] has demonstrated that approximately $100 \mathrm{~kW} / \mathrm{m}^{2}$ can be taken as a critical heat release rate for $10 \times 10 \mathrm{~cm}$ polymer stabs self-extinguishing in the absence of the application of external heat. Lyon reported [12] that using a critical value of $125 \pm 25 \mathrm{~kW} / \mathrm{m}^{2}$ is suitable for a correlation between intrinsic heat release rate and UL 94 . It was assumed that the data error is generally so large that the influence of thickness in the UL 94 classification and the differentiation between the classification as V0, V1 or V2 cannot be considered.

It is worth noting that the error $\pm 25 \mathrm{~kW} / \mathrm{m}^{2}$ for the intrinsic heat release rate data reported here also limits the possible differentiation between the classifications especially for V0 and V1. Furthermore, a good correlation between cone calorimeter data extrapolation and UL 94 cannot be expected, if the UL 94 behaviour is dominated by dripping properties. Therefore, we forbear from the prediction of V2 classification. Considering the reported critical value for self-extinguishing, the experimental data error and an estimated differentiation between V0 and V1, we set the following ranges for the propensity for propagation at an isolated flame, the intrinsic heat release rate, to predict the UL classification: $H R R_{0}<135 \mathrm{~kW} / \mathrm{m}^{2}$ : V0; $H R R_{0}=90-160 \mathrm{~kW} / \mathrm{m}^{2}: \mathrm{V} 1 ; H R R_{0}>115 \mathrm{~kW} / \mathrm{m}^{2}$ : HB. UL 94 classification is predicted in good correspondence to the real UL 94 results (Tab. 3).

The fire retarded PA-66 systems just barely achieve V0 classification. This is not surprising, since these materials are commercialised systems which can be expected to be optimised to reach the required UL classification for thin samples with as few fire retardants as possible. The investigated HIPS systems are not as good as the PA-66 systems, as was already indicated by the higher heat release rates. Furthermore, since the flammability considered in the UL 94 test corresponds to a small or 
even absent external heat flux, HIPS/red phosphorus is superior in comparison to HIPS/Mg(OH $)_{2}$ as was concluded in the previous discussion on the external heat flux dependency of the different mechanisms. In fact, the latter probably would not even achieve a $\mathrm{V}$ classification using this order of magnitude of $\mathrm{Mg}(\mathrm{OH})_{2}$ supplement, although this amount corresponds to previously reported data [19].

Tab. 3. UL 94 result prediction based on the $H R R_{0}$ and experimental UL $94[20,21]$ classification

\begin{tabular}{|c|c|c|c|c|c|}
\hline Sample & $\begin{array}{c}\text { UL } 94 \\
\text { predicted }\end{array}$ & $\begin{array}{c}\text { UL } 94 \\
{[1.6 \mathrm{~mm}]}\end{array}$ & Sample & $\begin{array}{c}\text { UL } 94 \\
\text { predicted }\end{array}$ & $\begin{array}{c}\text { UL } 94 \\
{[2.9 \mathrm{~mm}]}\end{array}$ \\
\hline A3EG5 & $\mathrm{V} 1, \mathrm{HB}$ & $\mathrm{HB}$ & HIPS & $\mathrm{HB}$ & $H B$ \\
\hline A3X3G5 & V0 & V1 & HIPS/red phosphorus & $\mathrm{HB}$ & V2 \\
\hline A3X2G5 & V0, V1 & V0 & $\mathrm{HIPS} / \mathrm{Mg}(\mathrm{OH})_{2}$ & $\mathrm{HB}$ & $\mathrm{HB}$ \\
\hline A3XZG5 & $\mathrm{V} 0, \mathrm{~V} 1$ & V0 & HIPS/red & V0, V1 & V1 \\
\hline A3EG7 & $\mathrm{V} 1, \mathrm{HB}$ & $H B$ & phosphorus/Mg $(\mathrm{OH})_{2}$ & & \\
\hline A3X3G7 & V0, V1 & V1 & & & \\
\hline A3X2G7 & V0, V1 & V0 & & & \\
\hline
\end{tabular}

\section{Conclusion}

The study clearly demonstrates that the variation of the external heat flux in cone calorimeter studies enables a comprehensive characterisation and assessment of the fire response of polymeric materials. The data are valuable for different fire scenarios and fire tests; even the prediction of a flammability test like UL 94 becomes possible via the characterization of fire response parameters. Furthermore, the comprehensive comparison of the effectiveness of fire retardants also provides a deeper understanding of the fire retardancy mechanisms.

Acknowledgement: The authors thank the BASF AG (Ludwigshafen, Germany), especially Dr. J. Engelmann and Dr. F. Gruber (both Polymer Laboratory), for their support, which has enabled us to carry out this work.

[1] Babrauskas, V.; "The Cone Calorimeter", in "Heat Release in Fires", Babrauskas, V.; Grayson, S. J.; editors; Elsevier Science Publishers LTD, Barking 1992, chap. 4, pp. 61-92.

[2] Lewin, M.; Weil, E. D.; "Mechanisms and Modes of Action in Flame Retardancy of Polymers", in "Fire Retardant Materials", Horrocks, A. R.; Price, D.; editors; Woodhead Publishing Ltd., Cambridge 2001, chap. 2, pp. 31-68.

[3] Green, J.; "Phosphorus-Containing Flame Retardants", in "Fire Retardancy of Polymeric Materials", Grand, A. F.; Wilkie, C. A.; editors; Marcel Dekker Inc., New York 2000, chap. 5, pp. 147-170.

[4] Schartel, B.; Kunze, R.; Neubert, D.; J. Appl. Polym. Sci. 2002, 83, 2060. 
[5] Schartel, B.; Kunze, R.; Neubert, D.; Braun, U.; "Mechanistic Studies on PA-66 Fire Retarded with Red Phosphorus", in "Recent Advances in Flame Retardancy of Polymers", vol. 13, Lewin, M.; editor; Business Communications Co. Inc., Norwalk 2002, pp. 93-103.

[6] Cullis, C. F.; Hirschler, M. M.; Tao, Q. M.; Eur. Polym. J. 1986, 22, 161.

[7] Davis, J.; Huggard, M.; J. Vinyl Additive Technol. 1996, 2, 69.

[8] Hornsby, P. R.; Fire Mater. 1994, 18, 269.

[9] Horn, W. E., Jr.; "Inorganic Hydroxides and Hydroxycarbonates: Their Function and Use as Flame-Retardant Additives", in "Fire Retardancy of Polymeric Materials", Grand, A. F.; Wilkie, C. A.; editors; Marcel Dekker Inc., New York 2000, chap. 9, pp. 285-352.

[10] Bourbigot, S.; Carpentier, F.; Le Bras, M.; Fernandez, C.; "Mode of Action of Zinc Borates in Flame retardant EVA-Metal Hydroxide Systems", in "Specialty Polymer Additives", Al-Malaika, S.; Golovoy, A.; Wilkie, C. A.; editors; Blackwell Science Ltd., London 2001, chap. 14, pp. 271-292.

[11] Hornsby, P. R.; Macromol. Symp. 1996, 108, 203.

[12] Lyon, R. E.; "Ignition Resistance of Plastics", in "Recent Advances in Flame Retardancy of Polymers", vol. 13, Lewin, M.; editor; Business Communications Co. Inc., Norwalk 2002, pp. 14-25.

[13] Tewarson, A.; "Generation of Heat and Chemical Compounds in Fires", in "SFPE Handbook of Fire Protection Engineering", $2^{\text {nd }}$ edition, Soc. of Fire Protection Engineering, Boston 1995, pp. 53-124.

[14] Lyon, R. E.; "Solid-State Thermochemistry of Flaming Combustion", in "Fire Retardancy of Polymeric Materials", Grand, A. F.; Wilkie, C. A.; editors; Marcel Dekker Inc., New York 2000, chap. 11, pp. 391-447.

[15] Lyon, R. E.; Fire Mater. 2000, 24, 179.

[16] Petrella, R. V.; J. Fire Sci. 1994, 12, 14.

[17] Hastie, J. W.; J. Res. Nat. Bur. Stand. Sect. A Phys. Chem. 1973, 77A(6), 733.

[18] Braun, U.; Schartel, B.; in preparation.

[19] Hirschler, M. M.; Thevaranjan, T. R.; Eur. Polym. J. 1985, 21, 371.

[20] BASF AG, Ultramid product information, KTMF 568 d 08.98, 1998.

[21] Engelmann, J.; unpublished results of BASF AG ZKT/U, 2002. 